\title{
Caracterização de proteínas do plasma seminal e sua relação com parâmetros de qualidade do sêmen criopreservado em ovinos
}

\author{
Characterization of seminal plasma proteins and its relationship with quality parameters of frozen \\ semen in ram
}

\begin{abstract}
Priscilla Pereira Moura' ${ }^{\mathrm{I}}$ Maurício Machaim Franco ${ }^{\mathrm{II}}$ Thiago Antônio de Souza Nascimento Silva ${ }^{\text {III }}$ Thales Lima Rocha" Diogo Ramos Leal ${ }^{\mathrm{III}}$ Pedro Ivo Braga Passos ${ }^{\mathrm{III}}$ Jairo Pereira Neves ${ }^{\mathrm{III}}$
\end{abstract}

\section{RESUMO}

Os objetivos deste trabalho foram analisar o perfil proteico do plasma seminal ovino e identificar proteínas relacionadas com a congelabilidade do sêmen que possam ser utilizadas como marcadores para essa característica. Foram utilizados os ejaculados de cinco reprodutores, nos quais foram realizadas avaliações espermáticas e dos quais os plasmas seminais obtidos por centrifugação foram submetidos à eletroforese bidimensional em gel de poliacrilamida. Foram identificados 92 spots, considerando todos os animais analisados. A avaliação dos dados obtidos evidenciou variações significativas nos resultados das análises do sêmen dos animais e uma variabilidade no perfil proteico no plasma seminal dos carneiros. As proteínas 03 (7,9kDa; pI 6,35), 23 (13,6kDa; pI 5,01) e 31 (21,4kDa; pI 4,75) se destacaram, por apresentarem maior expressão e relações com as características espermáticas. Sugere-se que mais estudos sejam realizados para verificar se as proteínas 03, 23 e 31 podem ser utilizadas como marcadores da capacidade criopreservadora do sêmen.

Palavras-chave: proteína, sêmen, carneiro, congelabilidade, eletroforese.

\section{ABSTRACT}

The objective of this study was to analyze the protein profile of ram seminal plasma and to identify proteins associated with semen freezability, which could be used as marker for predicting this feature. Semen from five rams was used. The sperm analysis was held and the seminal plasma obtained by centrifugation was submitted to two-dimensional electrophoresis using acrylamide gel. Ninety two spots were identified considering the analyzed animals. The results showed a significant variation among sperm analysis of the animals and variability in the protein profile of the seminal plasma of the rams. The proteins 03 (7.9kDa; pI 6.35), 23 (13.6kDa; pI 5.01) e 31 (21.4kDa; pI 4.75) stood out because they showed higher expression and because of its relationship with the sperm characteristics. It is suggested more studies to verify if proteins 03, 23 and 31 could be used as markers of semen freezability.

Key words: protein, semen, ram, frezability, electrophoresis.

\section{INTRODUÇÃO}

O crescimento da inseminação artificial tem ocorrido paralelamente ao desenvolvimento da tecnologia para utilização de sêmen congelado, cujo uso tem sido limitado em razão dos baixos índices de fertilidade conseguidos com a inseminação via cervical nos ovinos (MAXWELL \& WATSON, 1996). No carneiro, alguns aspectos da criopreservação promovem, na membrana espermática, uma maturação excessiva e aumenta precocemente a proporção de espermatozeides capacitados e acrossoma reagidos (HOLT, 2000).

Diversos estudos têm demonstrado que componentes do plasma seminal inibem a capacitação e possuem a habilidade de reverter os efeitos deletérios provocados pelo choque térmico, melhorando a viabilidade e heterogeneidade da membrana plasmática do sêmen criopreservado de carneiro (OLLERO et al., 1997; PÉREZ-PÉ et al., 2001). Os componentes do plasma seminal, especialmente as proteínas,

IFaculdade de Agronomia e Medicina Veterinária, Universidade de Brasília (UnB), 70910-900, Brasília, DF, Brasil. E-mail: plismoura@gmail.com. Autor para correspondência.

"Empresa Brasileira de Pesquisa Agropecuária (Embrapa), Brasília, DF, Brasil.

"IIUniversidade de Brasília (UnB), Brasília, DF, Brasil. 
desempenham um papel crucial em todos os processos relacionados com a capacidade fecundante dos espermatozoides. Com isso, diversos estudos estão sendo realizados com o objetivo de encontrar proteínas no plasma seminal ovino que possam ser utilizadas como possíveis marcadores da congelabilidade e da fertilidade do sêmen (STRYER, 1988; JOBIM et al., 2003)

O objetivo do presente estudo foi relacionar o perfil das proteínas do plasma seminal ovino com as características de congelabilidade do sêmen, identificando proteínas que possam ser utilizadas como possíveis marcadores dessa metodologia.

\section{MATERIAL E MÉTODOS}

Foram utilizados cinco reprodutores da raça Santa Inês, adultos, clinicamente sadios e mantidos com mesmo regime de alimentação. Cada reprodutor foi submetido a 16 coletas de sêmen com vagina artificial. O sêmen de oito coletas foi utilizado para a criopreservação, e o sêmen das outras oito coletas foi utilizado para obtenção das amostras de plasma seminal. Os animais foram separados em dois lotes: lote A $(79,145$ e 271) e lote B (05 e 21). Em cada dia de coleta o sêmen de um grupo era congelado e o do outro grupo era utilizado para separação do plasma. O intervalo entre as coletas era de 48 horas. Os ejaculados utilizados para criopreservação foram analisados considerando os seguintes itens: coloração, aspecto, odor, volume, turbilhonamento, motilidade, vigor, morfologia e concentração espermática.

O sêmen fresco foi submetido à avaliação de motilidade progressiva e integridade de acrossoma. As avaliações de motilidade foram realizadas em microscópio com contraste de fase, em aumento de 200x. A integridade do acrossoma foi determinada por microscopia de campo claro por meio da coloração dupla (Trypan-blue + Giemsa), segundo DIDION (1989). Foram contados 200 espermatozoides lâmina ${ }^{-1}$, que foram classificados em: vivo com o acrossomo íntegro (VI), vivo com o acrossomo reagido (VR), morto com o acrossomo íntegro (MI) e morto com o acrossomo reagido (MR).

Para criopreservação, procedeu-se à diluição do sêmen, ajustando-o a um total de $100 \times 10^{6}$ espermatozoides dose $\mathrm{e}^{-1} \mathrm{e}$ envasando-o em palhetas de $0,25 \mathrm{ml}$, na proporção de 1:1 (sêmen/meio diluidor), sob temperatura de $35^{\circ} \mathrm{C}$. O meio diluidor era composto por: solução A (1,4g de glicina; $2,97 \mathrm{~g}$ de citrato de sódio e $100 \mathrm{ml}$ de água destilada) e solução B (3g de frutose e $100 \mathrm{ml}$ de água destilada), sendo a solução final composta por $57 \mathrm{ml}$ de $\mathrm{A}+\mathrm{B}$ (solução $\mathrm{A}$; solução $\mathrm{B}$; $0,33 \mathrm{~g}$ de penicilina potássica e $0,100 \mathrm{~g}$ de dihidroestreptomicina); $20 \mathrm{ml}$ de gema de ovo; $15 \mathrm{ml} \mathrm{de}$ leite desnatado $11 \% ; 0,40 \mathrm{ml}$ de orvus es paste (OEP); $5 \mathrm{ml}$ de glicerol e $2,30 \mathrm{ml}$ de água destilada (Nutricell). Imediatamente após esses procedimentos, as palhetas com sêmen foram submetidas à refrigeração em refrigerador doméstico (Consul compacto 120 ), a $5^{\circ} \mathrm{C}$, por 90 minutos, para, então, serem transferidas para uma caixa de polietileno (isopor) contendo nitrogênio líquido, permanecendo por 20 minutos em vapor de nitrogênio e atingindo temperatura próxima de $-120^{\circ} \mathrm{C}$. Posteriormente, foram mergulhadas no nitrogênio líquido, acondicionadas em raques e armazenadas em botijão criogênico a $-196^{\circ} \mathrm{C}$.

Para as avaliações do sêmen criopreservado, as palhetas foram descongeladas a $37^{\circ} \mathrm{C}$, e o sêmen foi incubado na mesma temperatura, em banho-maria, por 240 minutos, sendo avaliado quanto à motilidade no momento da descongelação (hora 0) e aos 240 minutos (hora 4) e quanto à integridade de acrossoma e de membrana plasmática na hora 0 .

A motilidade e integridade de acrossoma foram avaliadas utilizando as mesmas técnicas utilizadas para o sêmen fresco. A integridade da membrana plasmática (IMP) foi avaliada utilizando-se uma combinação das sondas fluorescentes Diacetato de Carboxifluoresceína e Iodeto de Propídio (CFDAPI), como descrito por ZÚCCARI (1998). Foram contados duzentos espermatozoides/lâmina no microscópio de fluorescência. Os espermatozoides que apresentaram fluorescência verde foram considerados com membrana íntegra e os que apresentaram fluorescência vermelha ou verde e vermelha foram considerados com membrana lesada.

Para obtenção das amostras de plasma seminal, as amostras de sêmen foram submetidas a uma centrifugação a $1.500 \mathrm{~g}$, por cinco minutos, em temperatura ambiente, sendo o sobrenadante coletado e imediatamente armazenado a $-20^{\circ} \mathrm{C}$. Posteriormente, as amostras foram encaminhadas para análise, sendo novamente centrifugadas a $12.000 \mathrm{~g}$, por 10 minutos, a $4^{\circ} \mathrm{C}$, duas vezes. Em seguida, as amostras de plasma de cada animal e de cada partida foram aliquotadas e acondicionadas a $-80^{\circ} \mathrm{C}$, até a avaliação das proteínas.

As amostras de plasma seminal foram submetidas à eletroforese bidimensional, de acordo com o descrito por O' FARREL et al. (1977) e modificado por RODNIGHT et al. (1988). Foram formados dois pools dos plasmas de cada animal: um com as primeiras quatro amostras de plasma coletadas, e outro com as quatro últimas amostras de plasma coletadas. O pool 1 e o pool 2 de cada animal foram quantificados pelo método de Bradford (BRADFORD, 1976). Posteriormente, para caracterizar e comparar o perfil proteico, dois géis 
bidimensionais foram obtidos para cada animal, utilizando amostras de cada pool. Para isso, $200 \mu \mathrm{g}$ de proteínas de cada amostra foram suspensas e solubilizadas durante uma hora, sob temperatura ambiente, em $250 \mu \mathrm{L}$ de tampão de solubilização/ reidratação contendo 1\% de Ditiotritol (DTT), 2\% de gradiente imobilizado de pH - IPG (tampão) e $2 \%$ de CHAPS (3-[(3cholamidopropyl)-dimethylammonio]-1propanesulfonate). Em seguida, as amostras e tiras de 4-7L de $13 \mathrm{~cm}$ foram reidratadas por 16 horas.

No segundo dia, foi realizada a focalização isoelétrica. As condições dessa etapa foram as seguintes: 1) 300V, 2mA, 5W (1'); 2) 3500V, 2mA, 5W (1h30min); 3) 3500V, 2mA, 5W (5h). Todas as corridas foram realizadas a $18^{\circ} \mathrm{C}$. Após a focalização isoelétrica, as tiras foram acondicionadas individualmente em tubos de vidro sem nenhuma solução, a $-80^{\circ} \mathrm{C}$, até sua utilização para a segunda dimensão.

Para a segunda dimensão, foi realizada uma SDS-PAGE utilizando um gel a $12 \%$. As tiras foram retiradas do freezer $\left(-80^{\circ} \mathrm{C}\right)$ e foram equilibradas em $10 \mathrm{~mL}$ de tampão de equilíbrio mais $100 \mathrm{mg}$ de DTT, por 30 minutos, sob agitação à temperatura ambiente. Posteriormente, foram colocadas sobre a superfície do gel de acrilamida $(15 \mathrm{~cm} \times 14 \mathrm{~cm} \times 1 \mathrm{~mm})$ e fixadas com uma solução de agarose. As condições de corrida da eletroforese foram as seguintes: 1) $10 \mathrm{~mA}\left(15^{\prime}\right)$ e 2) $20 \mathrm{~mA}$ (5-7h50min). Os géis obtidos foram corados com solução de nitrato de prata. As análises das imagens foram realizadas no programa Image Máster 2D Platinum e foram consideradas a presença ou ausência dos spots observados.

Os dados foram analisados por meio do software SAS (Statistical Analysis System, edição 2.0, 2004) utilizando-se o procedimento GLM (análise de variância). $\mathrm{Na}$ análise dos dados das concentrações de proteínas totais foi utilizado o teste de Tukey. Para a correlação dos dados das avaliações espermáticas e das proteínas encontradas no plasma seminal foi utilizado o teste de Coeficientes de Spearman.

\section{RESULTADOS E DISCUSSÃO}

Os resultados obtidos a partir da eletroforese bidimensional evidenciaram uma variabilidade no perfil protéico, no plasma seminal dos carneiros. Foram identificados 92 spots (numerados de 1 a 92 para identificação), sendo considerados todos os animais analisados. Dos spots estudados, 29 $(31,52 \%)$ deles estavam presentes ou ausentes em apenas um animal. Pela análise dos géis obtidos, pôdese notar que existem diferenças marcantes e individuais entre os perfis de cada animal. JOBIM et al. (2005) detectaram 21 spots, com peso molecular variando de 15 a $115 \mathrm{kDa}$ e pI de 3,2 a 8,7 no plasma seminal ovino, por meio de eletroforese bidimensional.

As concentrações de proteínas totais presentes nos plasmas foram de $35,64 \mu \mathrm{g} \mu \mathrm{L}^{-1} ; 38,37 \mu \mathrm{g}$ $\mu \mathrm{L}^{-1} ; 36,86 \mu \mathrm{g} \mu \mathrm{L}^{-1} ; 32,99 \mu \mathrm{g} \mu \mathrm{L}^{-1}$ e $34,26 \mu \mathrm{g} \mu \mathrm{L}^{-1}$, encontradas nos animais $05,21,79,145$ e 271, respectivamente. Não foi observada diferença estatística entre os animais; porém, analisando-se apenas comparativamente os dados obtidos e correlacionando-os com observações realizadas por outros autores, verificou-se que existem similaridades nos resultados obtidos.

PÉREZ-PÉ et al. (2001) observaram que concentrações de proteínas do plasma seminal de 0,7 ; $1,4 \mathrm{e} 2,1 \mathrm{mg} \mathrm{ml}^{-1}$, depois de adicionadas ao sêmen, foram capazes de proteger espermatozoides ovinos contra os danos causados pela congelação dessas células, e a porcentagem de membranas intactas aumentou após uma hora de incubação no grupo com adição de maior concentração de proteínas. No presente estudo, observou-se que o animal com a maior concentração de proteínas totais (21) também apresentou os maiores resultados para integridade de membrana (Tabela 1 ).

Também foi possível verificar que o animal com a menor concentração de proteínas (145) apresentou os maiores resultados para a motilidade espermática após a descongelação. Esses resultados estão de acordo com os encontrados por JOBIM et al. (2003), que, estudando proteínas de baixo peso molecular do plasma seminal bovino, observaram que quanto maior a concentração de proteínas totais, menor a motilidade espermática pós-descongelação.

Os resultados verificados neste estudo e os citados por outros autores sugerem que a influência das proteínas do plasma seminal sobre os parâmetros de qualidade do sêmen está associada também ao tipo de proteína presente, pois, apesar da perda da integridade da membrana espermática ser um fator que contribui para o declínio da motilidade (ALMEIDA, 2006) e esperar-se que maior integridade de membrana esteja relacionada com maior motilidade, a presença e concentração de proteínas específicas podem influenciar cada uma dessas características.

SOUZA et al. (2004), estudando proteínas do plasma seminal de ovinos da raça Santa Inês, observaram que a maioria das proteínas do plasma seminal desses animais possuem peso molecular abaixo de $75 \mathrm{kDa}$ e pIs ácidos, e poucas apresentam pI acima de 8. Segundo BERGERON et al. (2005) e CARDOZO et al (2006), proteínas com peso molecular entre $14-24 \mathrm{kDa}$ foram as mais predominantes no plasma seminal ovino. Avaliando os géis obtidos neste experimento, foram 
Tabela 1 - Médias ( \pm desvio padrão) da Motilidade Espermática (\%) na hora quatro de descongelação; do CFDA-PI (\%) e do Trypan Blue Giemsa (\%) na hora zero (H0) da descongelação - Motilidade (MOT), Membranas íntegras (IMP), Espermatozoides Vivo íntegro (VI); Vivo reagido (VR); Morto íntegro (MI) e Morto reagido (MR).

\begin{tabular}{|c|c|c|c|c|c|c|}
\hline Animal & MOT & IMP & VI & VR & MI & MR \\
\hline 5 & $8,75 \pm 5,1^{\mathrm{D}}$ & $15,8 \pm 5,4^{\mathrm{B}}$ & $54,3 \pm 5,5^{\mathrm{C}}$ & $0,7 \pm 0,7^{\mathrm{AB}}$ & $44,0 \pm 5,4^{\mathrm{A}}$ & $0,9 \pm 0,6^{\mathrm{AB}}$ \\
\hline 21 & $23,12 \pm 10,3^{\mathrm{AB}}$ & $28,5 \pm 7,0^{\mathrm{A}}$ & $74,4 \pm 5,2^{\mathrm{A}}$ & $0,5 \pm 0,5^{\mathrm{AB}}$ & $24,3 \pm 5,3^{\mathrm{D}}$ & $0,6 \pm 0,5^{\mathrm{CB}}$ \\
\hline 79 & $13,75 \pm 8,7^{\mathrm{DC}}$ & $24,3 \pm 9,6^{\mathrm{A}}$ & $69,4 \pm 5,7^{\mathrm{AB}}$ & $1,1 \pm 1,5^{\mathrm{A}}$ & $28,1 \pm 6,2^{\mathrm{CD}}$ & $1,2 \pm 0,6^{\mathrm{A}}$ \\
\hline 145 & $27,50 \pm 7,0^{\mathrm{A}}$ & $28,1 \pm 7,3^{\mathrm{A}}$ & $62,6 \pm 7,9^{\mathrm{B}}$ & $0,1 \pm 0,1^{\mathrm{B}}$ & $36,8 \pm 7,9^{\mathrm{AB}}$ & $0,4 \pm 0,2^{\mathrm{C}}$ \\
\hline 271 & $17,50 \pm 7,0^{\mathrm{BC}}$ & $22,4 \pm 9,2^{\mathrm{AB}}$ & $65,0 \pm 10^{\mathrm{B}}$ & $0,1 \pm 0,2^{\mathrm{B}}$ & $34,2 \pm 9,9^{\mathrm{BC}}$ & $0,5 \pm 0,2^{\mathrm{CB}}$ \\
\hline
\end{tabular}

A,B,C,D letras diferentes na mesma coluna indicam diferenças significativas $(\mathrm{P}<0,05)$.

observados resultados similares no perfil proteico do plasma seminal, pois a maioria das proteínas encontradas apresentaram peso molecular abaixo de $70 \mathrm{kDa}$ e pI abaixo de 7.

Entre as proteínas diferencialmente expressas encontrou-se a proteína $21(15,5 \mathrm{kDa}$; pI 4,68), que apresentou correlação negativa com a motilidade espermática $(\mathrm{r}=-0,14 ; \mathrm{P}=0,07)$ e com a IMP $(\mathrm{r}=-0,34$; $\mathrm{P}=0,02)$ e estava presente nos animais 005 e 79 , que apresentaram as menores médias para esses parâmetros (Tabela 1). Tal resultado está de acordo com o encontrado por AL-SOMAI et al. (1994 a,b), os quais comentaram que as proteínas em maior concentração no plasma seminal, com peso molecular entre $15 \mathrm{e}$ $16 \mathrm{kDa}$, aniônicas, são desfavoráveis à motilidade espermática.

SOUZA et al. (2009) sugeriram que uma proteína de $45 \mathrm{kDa}$ e pI de 5,5 no plasma seminal caprino possui a função de proteger a célula espermática de danos causados no acrossoma. No presente estudo, foram encontradas duas proteínas, a $62(43,4 \mathrm{kDa}$; pI $5,30)$ e a $63(44,4 \mathrm{kDa} ;$ pI 5,33), que apresentaram correlação positiva com a quantidade de espermatozoides VI $(\mathrm{r}=0,19 ; \mathrm{P}=0,077)$ e com a IMP $(\mathrm{r}=0,47 ; \mathrm{P}=0,0019)$. Essas proteínas só não foram encontradas no animal 05 , que apresentou as piores médias em tais avaliações. Tais proteínas podem estar relacionadas com a manutenção da viabilidade espermática durante o processo de criopreservação e a ausência destas pode resultar em menor congelabilidade do sêmen.

A proteína $31(21,4 \mathrm{kDa} ; \mathrm{pI} 4,75)$ foi encontrada somente no animal 05 e apresentou alta expressão neste (Figura 1). Ela apresentou correlação negativa com a quantidade de espermatozoides VI $(\mathrm{r}=$ $0,19 ; \mathrm{P}=0,077)$ e com a IMP $(\mathrm{r}=-0,47 ; \mathrm{P}=0,0019)$. Esse animal apresentou os menores valores de IMP e espermatozoides VI, indicando uma possível relação entre essa proteína e menores parâmetros de qualidade no sêmen congelado.
O grupo de proteínas $03(7,9 \mathrm{kDa}$; $\mathrm{pI} 6,35)$, $23(13,6 \mathrm{kDa}$; pI 5,01), 85, 86, 88, 89, 90, 91 e 92 (56$70 \mathrm{kDa}$; pI 5,5-6,0) apresentou correlação positiva com a IMP (r=0,30; $\mathrm{P}=0,057)$, e o animal 21, que apresentou o melhor valor de IMP, foi o único que apresentou tais proteínas.

As proteínas 03 e 23 se destacaram em razão da alta expressão no animal 21, como pode ser observado nos géis deste (Figura 1). As proteínas 02 (8,5kDa; pI 5,0-5,5), 17 (11,5kDa; pI 5,81); 69, 70, 71, 72 e $79(64-80 \mathrm{kDa}$; pI 4,5-5,5) apresentaram correlação positiva com a IMP $(\mathrm{r}=0,5 ; \mathrm{P}=0,001)$ e não foram encontradas somente nos animais 05 e 271, que apresentaram os menores resultados para IMP. Tais proteínas podem estar relacionadas com a integridade de membrana plasmática e com a viabilidade espermática. Elas podem exercer um efeito protetor na integridade da membrana espermática, que é essencial para a manutenção da funcionalidade do espermatozoide e é necessária para a capacitação, reação de acrossoma e penetração no ovócito.

De acordo com suas características de peso molecular e pI, algumas dessas proteínas podem fazer parte da família de proteínas BSPA1/A2. JOBIM et al. (2005) encontraram dois spots similares às proteínas BSP A1/A2 no plasma seminal de ovinos, um com 18$19 \mathrm{kDa}$ - pI 4.8-5.0 e o outro com 17-18kDa - pI 5.0-5.2. Tais proteínas também poderiam corresponder às caltrinas, que são proteínas decapacitantes do plasma seminal que possuem baixa massa molecular ( 5 a 10kDa) e previnem o aumento da concentração de $\mathrm{Ca}^{2+}$ nos espermatozoides, evitando a capacitação espermática precoce provocada pelo processo de criopreservação (FLESCH \& GADELLA, 2000). SOUZA et al. (2009), em estudos sobre proteínas do plasma seminal caprino relacionadas com o índice pluviométrico e a qualidade do sêmen, encontraram proteínas com massas moleculares relativas de 4 a 10kDa no período de alto índice pluviométrico, no qual foi observado maior porcentual de células vivas com acrossomas íntegros. 


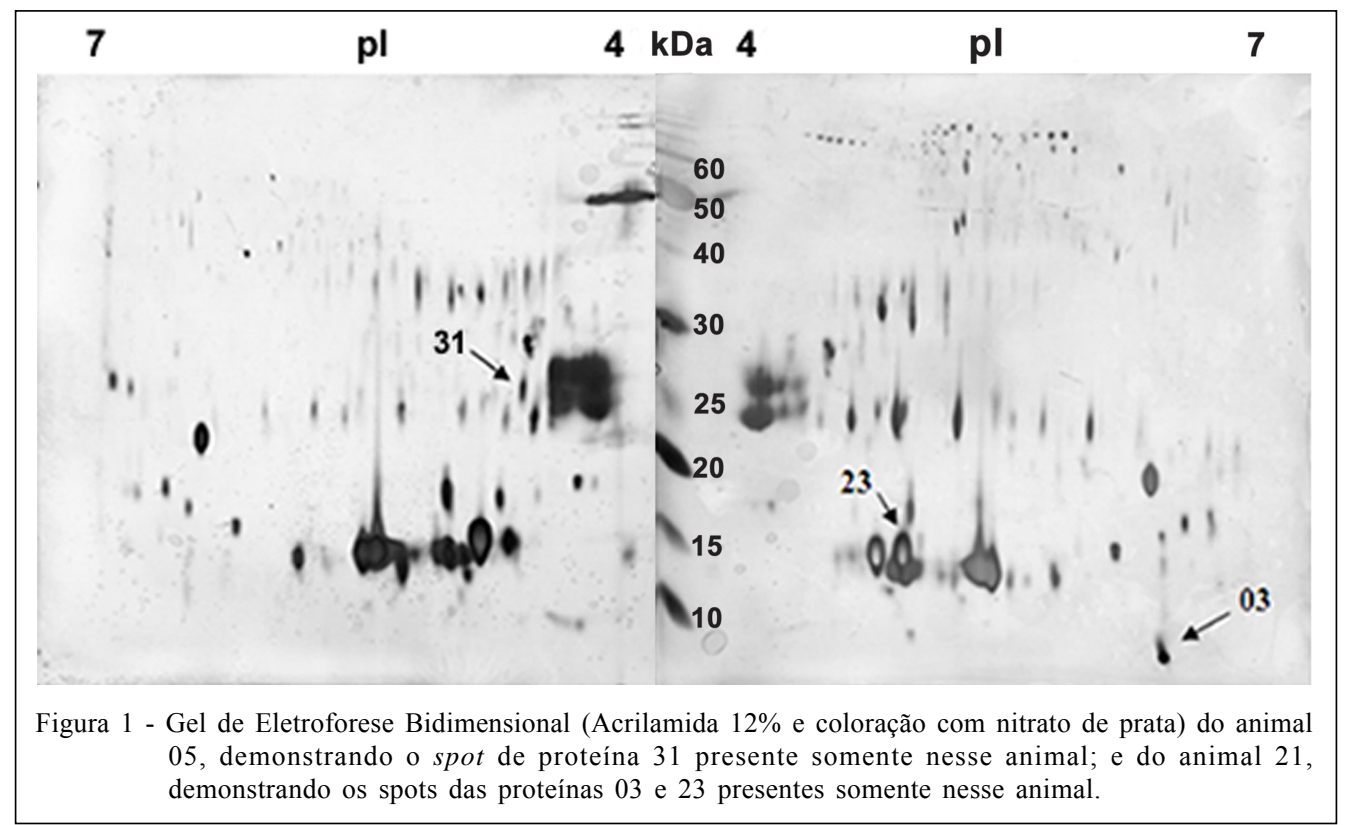

Os resultados encontrados indicam que o plasma seminal ovino contém proteínas que estão envolvidas em características fundamentais para a adequada função do espermatozoide e para incrementar sua capacidade de criopreservação. Sugere-se que as proteínas 03, 23 e 31 podem ser possíveis marcadores da congelabilidade do sêmen. A proteína 31 como indicador protéico da menor congelabilidade do sêmen e as proteínas 03 e 23 como marcadores da maior congelabilidade do sêmen.

As observações realizadas neste estudo também evidenciam a existência de diferenças no perfil proteico de reprodutores com diferentes resultados de criopreservação do sêmen e sugerem que diversas proteínas no plasma seminal atuam de maneira complementar e que essas proteínas possuem um papel importante na estabilidade da membrana e, consequentemente, na viabilidade e motilidade espermática.

\section{CONCLUSÕES}

Os resultados obtidos neste estudo podem ser utilizados como subsídio para aumentar a viabilidade da utilização do sêmen ovino congelado para uso na inseminação artificial transcervical nessa espécie. Novos estudos envolvendo a caracterização dessas proteínas são importantes para o estabelecimento de marcadores moleculares para a congelabilidade do sêmen ovino.

\section{COMITÊ DE ÉTICA E BIOSSEGURANÇA}

O trabalho não foi submetido ao comitê de ética, pois não foi utilizado nenhum procedimento que comprometesse a integridade e o bem-estar dos animais.

\section{REFERÊNCIAS}

ALMEIDA, J.L. Efeito de diferentes concentrações de plasma seminal na criopreservação do sêmen eqüino. 2006. 77f. Dissertação (Mestrado em Ciências agrárias) Universidade de Brasília/Faculdade de Agronomia e Medicina Veterinária, Brasília, DF.

AL-SOMAI, N. et al. Anionic and cationic components from protein aggregates in bovine seminal plasma and their effects on sperm motility. Molecular Reproduction and Development, v.39, p.328-336, 1994b. Disponível em: <http:/ /www.ncbi.nlm.nih.gov/pubmed/7888171>. Acesso em: set. 2008. doi: $10.1002 / \mathrm{mrd} .1080390310$.

AL-SOMAI, N. et al. Low molecular weight components in bovine semen diffusate and their effects on motility of bull sperm. Journal of Reproduction and Fertility, v.41, p.165171, 1994a. Disponível em: <http://www.ncbi.nlm.nih.gov/ pubmed/7991784>. Acesso em: out. 2008. doi:10.1071/ RD9940165.

BERGERON, A. et al. Isolation and characterization of the major proteins of ram seminal plasma. Molecular Reproduction and Development, v.71, p.461-470, 2005. Disponível em: <http://www3.interscience.wiley.com/journal/ 110494312/abstract?CRETRY $=1 \&$ SRETRY $=0>$. Acesso em: nov. 2008. doi: $10.1002 / \mathrm{mrd} .20310$.

BRADFORD, M.M. A rapid and sensitive method for the quantitation of microgram quantities of protein utilizing the 
principle of protein-dye binding. Analytical biochemistry, v.72, p.248-254, 1976. Disponível em: <http:// www.ncbi.nlm.nih.gov/pubmed/942051>. Acesso em: jan.2008. doi: 10.1016/0003-2697(76)90527-3.

CARDOZO, J.A. et al. Monthly variations in ovine seminal plasma proteins analyzed by two-dimensional polyacrylamide gel electrophoresis. Theriogenology, v.66, p.841-850, 2006. Disponível em: <http://www.theriojournal.com/article/S0093691X(06)00074-4>. Acesso em: set. 2008. doi: 10.1016/ j.theriogenology.2006.01.058.

DIDION. B.A. et al. Staining procedure to detect viability and the true acrosome reaction in spermatozoa of various species. Gamete Research, v.22, n.1. p.51-57, 1989. Disponível em: $<$ http://www3.interscience.wiley.com/journal/109927224 abstract>. Acesso em: set.2008. doi: 10.1002/mrd.1120220106.

HOLT, W.V. Fundamental aspects of sperm cryobiology: the importance of species and individual differences. Theriogenology, v.53, p.47-58, 2000. Disponível em: <http:/ /www.theriojournal.com/article/S0093-691X(99)00239-3>. Acesso em: set. 2008. doi: 10.1016/S0093-691X(99)00239-3.

JOBIM, M.I.M. et al. Proteínas de baixo peso molecular do plasma seminal bovino relacionadas com a congelabilidade do sêmen através de eletroforese bidimensional em gel de poliacrilamida. Acta Scientiae Veterinariae, v.31 p.21-30, 2003.

JOBIM, M.I.M. et al. BSP A1/A2-like proteins in ram seminal plasma. Theriogenology, v.63, p.2053-2062, 2005. Disponível em: <http://www.ncbi.nlm.nih.gov/pubmed/15823360>. Acesso: nov. 2008. doi:10.1016/j.theriogenology.2004.10.002.

MAXWELL, W.M.C., WATSON, P.F. Recent progress in the preservation of ram semen. Animal Reproduction Science, v.42, p.55-65, 1996. Disponível em: <http://www.ingentaconnect.com/ content/els/03784320/1996/00000042/00000001/art01544>. Acesso em: jan. 2008. doi: 10.1016/0378-4320(96)01544-8.

O'FARREL, P.Z. et al. High resolution of two-dimensional electrophoresis of basic as well as acidic proteins. Cell, v.12: p.1133-42, 1977. Disponível em: <http://www.ncbi.nlm.nih.gov/ pubmed/23215>. Acesso em: set.2008. doi: 10.1016/00928674(77)90176-3.
OLLERO, M. et al. Surface changes of ram spermatozoa by absorption of homologous seminal plasma proteins revealed by partition in aqueous two-phase system. Reproduction, Fertility and Development, v.9, p.381-390, 1997. Disponível em: <http://www.ncbi.nlm.nih.gov/pubmed/9402246>. Acesso em: nov. 2008. doi:10.1071/R96037.

PÉREZ-PÉ, R. et al, T. Semen plasma proteins prevent coldshock membrane damage to ram spermatozoa. Theriogenology, v.56, p.425-434, 2001. Disponível em: $<$ http://www.journals.elsevierhealth.com/periodicals/the/article/ PIIS0093691X0100574X>. Acesso em: set. 2008. doi: 10.1016/S0093-691X(01)00574-X.

RODNIGHT, R. et al. An investigation of experimental conditions for studying phosphorylation in micro-slices of rat brain by two-dimensional electrophoresis. Journal of Neuroscience Methods; v.24, p.27-38, 1988. Disponível em: <http://www.ncbi.nlm.nih.gov/pubmed/3386300>. Acesso em: out. 2008. doi: 10.1016/0165-0270(88)90030-1.

SOUZA, C. E. et al. Seminal plasma proteins, testis development and sêmen criteria in the ram. In: Annual Meeting of the American Society of Andrology, 29., 2004, Baltimore, Maryland. Proceedings... Baltimore: American Society of Andrology, 2004. p. 91 (abstract).

SOUZA, A. F. et al. Proteínas do plasma seminal de caprinos relacionadas com o índice pluviométrico e a qualidade do sêmen. Ciência Rural, v.39, n.4, p.1166-1172, 2009. Disponível em: $<$ http://www.scielo.br/scielo.php?script=sci_arttext\&pid=S010384782009000400030>. Acesso em: set. 2009. doi: 10.1590/ S0103-84782009005000044.

STRYER, L. Introduction to biological membranes. In: STRYER, L. Biochemistry. 3.ed. New York: Freeman and Company, 1988. p.83-310.

ZÚCCARI, C.E.S.N. Efeito da criopreservação sobre a integridade estrutural da célula espermática equina. 1998. 118F. Tese (Doutorado em Reprodução Animal) Faculdade de Medicina Veterinária e Zootecnia, Campus Botucatu, Universidade Estadual Paulista, Botucatu, SP. 